\title{
Copper Nanoparticles as Modulators of Apoptosis and Structural Changes in Tissues
}

\author{
Elena Sizova ${ }^{1}$, Sergey Miroshnikov ${ }^{1}$, Valentina Polyakova ${ }^{2}$, Natalia Gluschenko ${ }^{3}$, Anatoly Skalny ${ }^{1}$ \\ ${ }^{1}$ Orenburg State University, Orenburg, Russia; ${ }^{2}$ Orenburg State Medical Academy of Federal Agency in Public Health and Social \\ Development, Orenburg, Russia; ${ }^{3}$ Institute of Energy Problems in Chemical Physics RAS, Moscow, Russia. \\ Email: Sizova.L78@yandex.ru
}

Received October $16^{\text {th }}, 2011$; revised November $29^{\text {th }}, 2011$; accepted December $20^{\text {th }}, 2011$

\begin{abstract}
Results of research on copper nanoparticles influence on index of readiness to apoptosis and structural changes of liver, spleen, kidney tissues as well as sensomotor cerebral cortex under copper multiple introductions into organism of animals are presented in the article. It is established that copper nanoparticles distribute in organs and tissues of animals and cause specific structural changes. The increase of copper nanoparticles in organism up to toxical threshold (maximum tolerated dose) results in dystrophy and tissue necrosis. Accurate expression enhancement of Caspase 3 in microgliocytes (brain macrophages) has been registered seven days after one-fold intramuscular introduction of copper nanoparticles (dose $2 \mathrm{mg} / \mathrm{kg}$ of animal body weight), in liver cells - three and seven days after three-fold intramuscular introduction of copper nanoparticles (total dose was $6 \mathrm{mg} / \mathrm{kg}$ of animal body weight), in proximal kidney tubules-three hours, one, three and seven days after three-fold intramuscular introduction of copper nanoparticles (with total dose 6 $\mathrm{mg} / \mathrm{kg}$ of animal body weight), in spleen cells three hours, one, three and seven days after 12-fold intramuscular introduction (with total dose $24 \mathrm{mg} / \mathrm{kg}$ of animal body weight). Received data enables us to propose using index of cells readiness to apoptosis defined by Caspase 3 expression as a criterion for copper nanoparticles introduction safety assessment.
\end{abstract}

Keywords: Apoptosis; Copper Nanoparticles; Microelements; Spleen; Liver

\section{Introduction}

Development of modern technologies allows solving many medical and vetting problems. It is development of new materials for surgery and effective drug delivery systems, diagnostics and control over patient treatment, use nanomaterials for new medicines and biological preparations. At present metallotherapy is generally recognized medical sect, where organic and inorganic salts, metal complexes are used. Along with traditional medicines, containing metal, new ones having nanoparticles appear. Thus there are bandages with nanocrystalline silver for healing wounds, burns and trophic ulcer [1]. Indeed, nanometal characteristics differ from that of bulk samples and single atoms. Our researches on different elements nanoparticles allow us to establish that their toxicity is 7 times - 50 times less comparing to salts, they have multifunctional and durable action, easily penetrate into all organs and tissues, stimulate metabolic processes when used in biotic doses, etc. [2-5]. At the same time mentioned peculiarities of nanoparticles can promote different pathological conditions in living systems and might even cause death. That's why so many articles focus on living systems' re- sponse to nanomaterials: analysis of pulmonary tissue using nanocarbon tubes [6], brain edema formation and malfunction of blood-brain barrier under the influence of silver, copper, aluminium, silicon, carbon nanoparticles and metal oxides [7], study of central nervous system under the influence of silver nanoparticles and copper oxide [8], dopaminergic system under the influence of $\mathrm{Mn}, \mathrm{Ag}$, $\mathrm{Cu}$ nanoparticles [9]. There are also analyses of clinical and biochemical indexes of urine, serum, liver and kidney tissues at copper nanoparticles introduction in different doses [10]; DNA damage degree and cytotoxicity of different metal oxides [11] is also studied. Comparative researches on nanoparticle toxicity continue, for example, copper in comparison with microparticles and metal ions [12]. At present, nanomaterials toxicity is connected with oxidative stress and DNA damage [13]. But other toxicity mechanisms are also considered. For instance, their damaging action on cytomembranes and organelles accelerates transportation of potentially toxic elements. Genotoxic and allergenic action is also possible [14].

At the same time there are no data on the structural and functional change of tissues under increasing metal nanoparticles introduction into organism of animals; there 
are no criteria, which can help to decide an issue of safety of this nanomaterial introduction into organism. In this connection, this article presents actual researches on change of apoptosis that is a marker of programmed cell death and tissue structure under increasing introduction of copper nanoparticles into the organism of animals.

\section{Materials and Methods}

The research was conducted on male Wistar with weight $150 \mathrm{~g}-180 \mathrm{~g}$ that received common ration in vivarium; animals were weekly intramuscularly injected with aqueous suspension of copper nanoparticles in dosage of 2.0 $\mathrm{mg} / \mathrm{kg}$ animal weight. Another group of animals were watered with suspended mixture of copper nanoparticles in dosage of $2.0 \mathrm{mg} / \mathrm{kg}$ animal weight for 3 days. Experimental research on animals was conducted according to instructions, recommended by the Russian Regulations, 1987 and "The Guide for Care and Use of Laboratory Animals (National Academy Press Washington, D.C. 1996)". Copper nanoparticles were obtained with high temperature condensation method using app Migen-3 $[15,16]$. Water suspension of copper nanoparticles for injections and watering was prepared according to the following scheme: prepare nanopowder dry weight, dissolve it in water, consecutive suspension dispergating using ultrasound dispersion machine UZDN-2T in this mode: three-fold dispergating for 1 minute with 3 minute pause. Test samples for the analysis of structural and functional status of liver were taken 3 hours, 1 day, 3 and 7 days after each injection and in 1 hour, 2 hours after enteral introduction of nanoparticles water suspension. Animals of control group were intramuscularly injected and enterally watered with distilled water in the same volume as tested animals.

To research structural and functional condition of organs and tissues samples were for 1 day fixed in $10 \%$ neutral formaline at a room temperature. After standard histological preparation samples were embedded in paraffin. Paraffin-embedded slices of $5 \mu \mathrm{m}$ thickness were stained by Mayer's hematoxylin and eosin. To detect exogenic copper nanoparticles benzidine staining of paraffin-embedded slices was also used [17]. Glycogen in liver was detected with Hotchkiss-Mcmanus-Shabadash PAS reaction [17]. Ki-67 expression index was used to assess cell proliferative activity and to identify cell readiness to apoptosis-Caspase-3 expression. Immunohistochemical researches were carried out on paraffin slices with the use of monoclonal antibodies and imaging system "Bio Genex Super Sensytive Detection System" (USA) according to the records of the producer. Fragmented DNA in hepatocytes was identified using ApopTag (Plus Peroxidase in situ Apoptosis Detection Kit-S 71010) in accordance with records of the producer (Intergen, USA). Immuno- positive cell were counted among 1000 and expressed in $\%$.

Statistical processing of received data was performed using software package "Statistica 5,5 for Windows" and "MS Excel 2000". Validity of compared indexes differrences was determined by t-criterion of Student. Results at $\mathrm{p} \leq 0.05$ were considered valid.

\section{Results and Discussion}

\subsection{Structural Changes in Tissues of Animals at Copper Nanoparticles Introduction}

Copper nanoparticles were synthesized using high temperature condensation method with their subsequent modification with oxygen in order to study influence of copper nanoparticles on structure of tissues and organs [15, 16]. The research of physical and chemical characteristics revealed the following: copper nanoparticles have spherical form; average size is $103.0 \mathrm{~nm} \pm 2.0 \mathrm{~nm}$; nanoparticle nucleus contains $96.0 \% \pm 4.5 \%$ crystal copper, $-4.0 \% \pm 0.4 \%$ copper oxide; thickness of oxide film on the surface is $-6 \mathrm{~nm}[18]$.

Recent researches on biological action of unmodified copper nanoparticles after one-fold subcutaneous introduction allow to establish nanoparticle regular effect on the organism depending on the metal dosage. This effect can be described by the generalized curve "dosage-response" in the following form: 1) biotic zone of copper nanoparticles is within dosages that 2 times-250 times less toxical threshold-maximum permissible dose (MPD); 2) "safety" zone (when stimulatory action isn't expressed and toxic effect doesn't become apparent) is within dosages $15 \mathrm{mg} / \mathrm{kg}-25 \mathrm{mg} / \mathrm{kg}$; 3) pharmacotoxic action for copper nanoparticles begins from dosage $25 \mathrm{mg} / \mathrm{kg}, \mathrm{LD}_{50}$ $45 \mathrm{mg} / \mathrm{kg}, \mathrm{LD}_{100} 60 \mathrm{mg} / \mathrm{kg}$. Copper nanoparticles toxicity is 6 times less at $\mathrm{LD}_{100}$ toxic index of copper sulfate [19]. Comparing toxicity indexes of copper nanoparticles modified by oxygen, which we used in our research, and unmodified nanoparticles it was established that modified nanoparticles are 2 times more biologically active.

Thus, pharmacotoxic zone for them begins from dosage $10 \mathrm{mg} / \mathrm{kg}$ (MPD), $\mathrm{LD}_{50}$ is $15 \mathrm{mg} / \mathrm{kg}, \mathrm{LD} 1_{100} 30 \mathrm{mg} / \mathrm{kg}$ [20]. Taking these data into account, a single introduction dosage of $2 \mathrm{mg} / \mathrm{kg}$ allowing to reach MPD $10 \mathrm{mg} / \mathrm{kg}$ at a 5-fold copper nanoparticles introduction, a dosage close to $\mathrm{LD}_{100} 24 \mathrm{mg} / \mathrm{kg}$ at a 12 -fold introduction was taken to study the structural and functional status of animal organs and tissues while increasing load of copper nanoparticles on the organism. The difference in rates of acute toxicity of nanoparticles received by one method, but modified by various factors indicate the need to control physical and chemical properties of metals in their further use as a substrate for the development and creation of drugs and biologicals. 
During the study of the liver 3 hours after one-fold intramuscular introduction of copper nanoparticles in dosage of $2 \mathrm{mg} / \mathrm{kg}$ copper nanoparticles (Figure 1) can be seen in the vascular part of the periportal hepatocytes and in the Kupffer cells cytoplasm of the experimental animals liver, which disappear within 3 days after the introduction. At the same time no structural changes in the organism have been identified.

In the vascular part of the periportal hepatocytes and in the Kupffer cells cytoplasm of the experimental animals liver an amorphous moderately blue staining (indicated with the arrow) of exogenous copper can be seen using the modified benzidine staining on histological liver sections.

However, in periportal hepatocytes, there are signs of hydropic degeneration, which is not revealed during the study of an organism 7 days after a one-fold introduction of the metal. At a repeated intramuscular introduction of copper one week later nanoparticles are revealed mainly in the vascular part of the periportal hepatocytes. Herewith one day after the second metal introduction signs of hydropic degeneration are revealed in the vascular part of periportal hepatocytes. Apoptotic Kaunsilmen cells also appear among hepatocytes (Figure 2 (a) and (b)).

As compared to the control rats 1) in experimental rats hepatocytes; 2) vacuolation of the cytoplasm (indicated by an arrow) is observed and oxyphilic apoptotic Kaunsilmen cells are revealed (1). At the enteral introduction of copper nanoparticles 2 hours after the first watering there structural changes in liver with signs of hydropic degeneration in the periportal zone hepatocytes could be seen. 3 days after enteral introduction of copper nanoparticles organ structure is not changed. There are no nanoparticles in the liver hepatocytes, but they are found in the Kupffer's cells. Studingy liver 2 hours after the third enteral introduction, copper nanoparticles are present in Kupffer's cells and the hepatocytes vascular zone. Herewith there were no signs of degeneration in cells.

Studing spleen structural organization in response to the increased load of copper on the organism we have found that copper nanoparticles could be seen in the red pulp of spleen, mainly in macrophages first day after intramuscular metal introduction and remain after subsequent introductions. One-fold introduction of copper nanoparticles does not affect spleen structural homeostasis, but promotes a moderate increase of functional activity of the white pulp, the increase of its relative mass density, relative mass density of germinal centers, periarterial lymphoid clutches and increased rates of the number of cells per unit of area in these zones testify to that fact. Morphometric parameters of the white pulp after 2 and 3 injections of nanoparticles also attest to the increase of its functional activity. More significant changes in morphometric parameters of the white pulp could be seen 7 days after the repeated introduction of copper nanoparticles. Increase in lymphoid follicles after the second introducetion of copper nanoparticles takes place not only due to increase of germinal centers, where there are processes of blast transformation and lymphocytes reproduction, but in the majority of follicles by means of mantle and marginal zones, where processes of differentiation and cell moving into the red pulp take place.

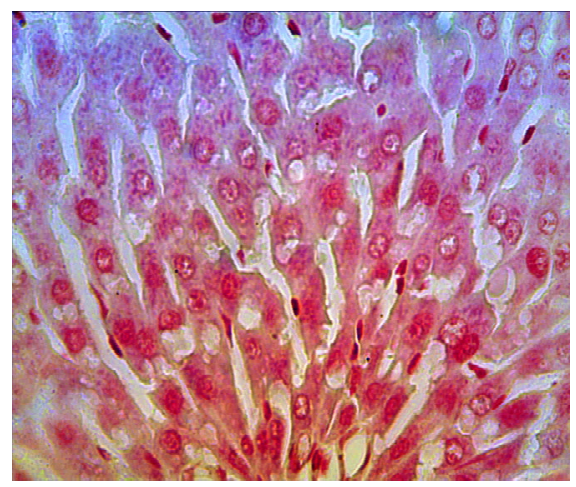

Figure 1. Histological section of the rat liver fragment 3 hours after one-fold intramuscular introduction of copper nanoparticles in dosage of $2 \mathrm{mg} / \mathrm{kg}$.

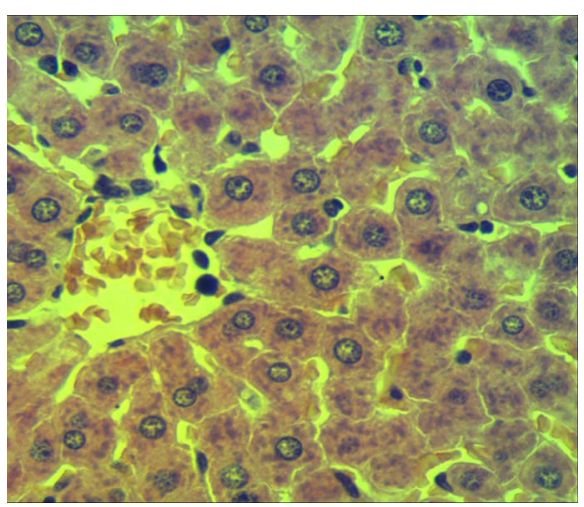

(a)



(b)

Figure 2. Histological liver section of the control (a) and the experimental rat (b) 1 day after the repeated intramuscular introduction of copper nanoparticles in the dosage of $2 \mathrm{mg} / \mathrm{kg}$. 
Nanoparticles of copper could be found in cells of proximal kidney tubules during first days after one-fold intramuscular metal introduction. Locally there are hyaline-drop and hydropic dystrophy phenomena in individual tubule cells. However, these phenomena could not be seen within 7 days after the introduction. Kidney glomerules have not been changed, but macrophages expressing Caspase 3 could be found in the interstitial tissue more frequently than in the control one. After the second and particularly after the third intramuscular injection of copper nanoparticles the number of tubules with signs of protein dystrophy increases. Epithelial cells having necrosis appear in the tubules, local damages of the basal tubules membrane have been also identified (Figure 3).

There are hyaline-drop and hydropic dystrophy phenomena (1) in tubule cells and their necrosis in places (indicated with the arrows).

Nanoparticles are found in all proximal tubules after one-fold enteral introduction of nanoparticles as well as after intramuscular introduction. In some of them there are hyaline dropwise and hydropic dystrophy.

After a three-fold enteral introduction, along with protein dystrophy phenomena the necrosis of some epithelial cells in tubules is revealed, but the basal membrane is not damaged that is good for the prediction of the regeneration process in these tubules.

Structural changes in the organs of the experimental group in comparison with the control one were not found after one-fold intramuscular introduction of copper nanoparticles into the sensomotor zone of cerebral cortex. Benzidine staining had no positive results, probably due to the small amount of nanoparticles that entered tissue elements of the nervous system.

These data suggest that copper nanoparticles can easily penetrate into all organs and tissues at both intramuscular and enteral introduction. Specific structural changes are observed depending on the type of tissue, the total dosage of introduced nanoparticles and the response time. In case of copper nanoparticles load increase (total dosage of $4 \mathrm{mg} / \mathrm{kg}$ and $6 \mathrm{mg} / \mathrm{kg}$ ) the phenomena of dystrophy and tissue necrosis are revealed in the studied tissues. Enteral way of nanoparticles introduction is safer than intramuscular one.

\subsection{Expression of Apoptosis Marker after the Introduction of Copper Nanoparticles}

Changes in the index of cell readiness to apoptosis, programmed necrocytosis, take place together with structural reorganization of tissues under the influence of copper nanoparticles. It is known that apoptosis is a form of necrocytosis, during which self-destruction occurrs as a result of DNA damage in a cell nucleus and it could not be resolved by a repair system. A protein encoded by the gene $\mathrm{p} 53$ follows this process. If it is impossible to resolve the DNA damage an apoptosis is activated under the action of protein53 [21]. It is known that trace elements play an important role in apoptosis regulation, which may intensify the effect of deficit and excess of elements, or as a result of vital trace elements imbalance. Thus zinc is a selective inhibitor of apoptosis, manganese, cadmium, lead, gallium, etc. are able to modulate an apoptosis, i.e. effect differently depending on the dosage [22]. Such elements as selenium, zinc, iron, copper prevent realization of a gene-damaging action [23,24]. Taking into account these data, we have studied the readiness of various tissue cells to apoptosis, estimated by antigen expression of Caspase 3 in case of copper nanoparticles load increase on the organism. The results are presented in the Table 1 below.

In the liver of control animals the expression of Caspase 3 can be found only among centrolobular hepatocytes and it is $0.7 \%$ o $\pm 0.03 \%$. Apoptag-positive cells are also seen among centrolobular hepatocytes and they are $0.5 \% \pm 0.02 \%$. After repeated intramuscular introduction of copper nanoparticles the cells expressing Caspase 3 antigen as well as having positive respond on a fragmented DNA are discovered among the periportal heaptocytes. The difference of markers expression of cell readiness to apoptosis is reliable in comparison to liver of the control group of animals 3 days and 7 days after three-fold intramuscular nanoparticle introduction. Expression indexes increase twice $(\mathrm{p}<0.05) 7$ days after three-fold intramuscular introduction (Table 1).

During the immunohistochemical study of a proliferative cell activity of lymphoid spleen follicles using antibodies Ki-67 it has been revealed that 7 days after the second introduction of nanoparticles the expression Ki-67 has increased two times in comparison with the control

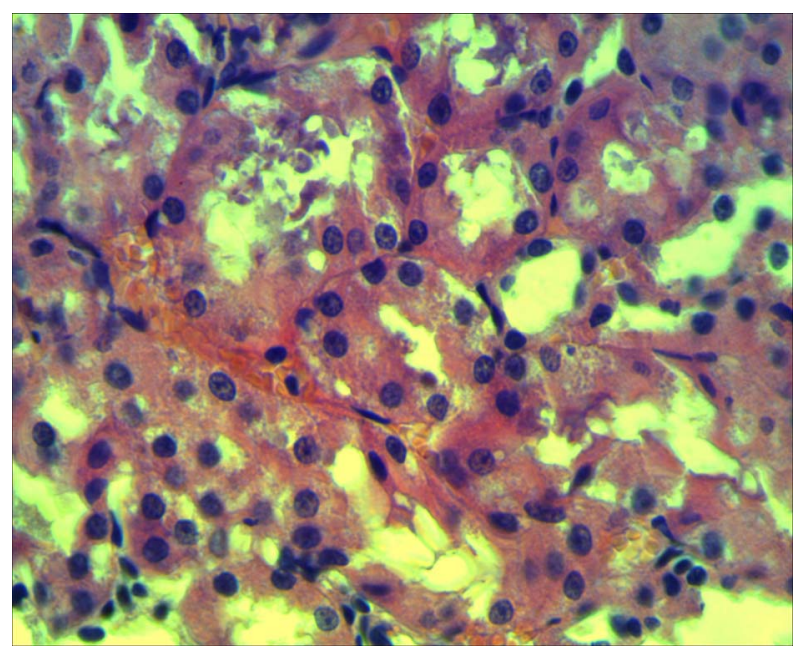

Figure 3. Histological section of kidney cortex of the experimental rat 7 days after the third intramuscular introducetion of copper nanoparticles in a dosage of $2 \mathrm{mg} / \mathrm{kg}$. 
Table 1. The indexes of Caspase 3 antigen expression $(*, * *)$ in tissue cells after repeated intramuscular introduction of copper nanoparticles in the dosage of $2 \mathrm{mg} / \mathrm{kg}$ (in \%o).

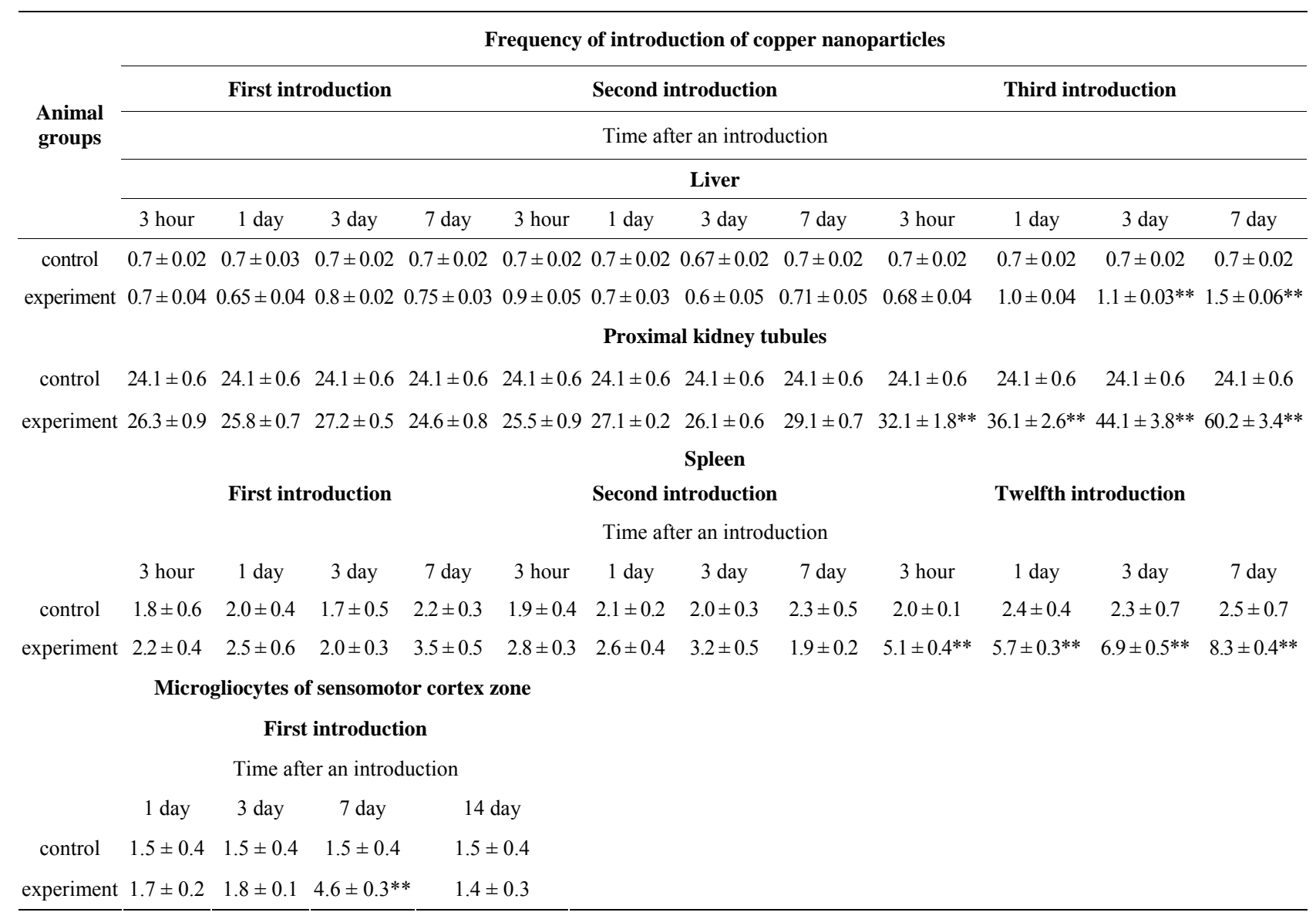

*Data presented as: average $(\mathrm{X}) \pm$ standard error of the average $(\mathrm{SE})(\mathrm{n}=1000) ; * *$ results are statistically significant $(\mathrm{p}<0.05)$.

one and decreased 1.5 times 7 days after the $12^{\text {th }}$ injecttion of copper nanoparticles in comparison with the control group $(\mathrm{p}<0.05)$. The study of follicular cells readiness to apoptosis has revealed a reduction of Caspase 3 antigen expression 7 days after the second injection of nanoparticles. Seven days after the $12^{\text {th }}$ injection the number of cells of lymphoid spleen follicles expressing Caspase 3 antigen increases, indicating an increased readiness of follicular cells to apoptosis (Table 1).

The readiness of kidney tubule epithelial cells to apoptosis significantly increases after the second and particularly after the third intramuscular injection of copper nanoparticles. If the antigen expression of Caspase 3 in tubular epithelium of the control animals was $24.1 \%$ o $0.6 \%$, after the third intramuscular injection of copper nanoparticles indexes increase 2.5 times $(p<0.05)$ in comparison with the control (Table 1) ones.

Immunohistochemical detection of cells expressing $\mathrm{Ca}-$ spase 3 antigen in the sensomotor cortex zone revealed the readiness of cells to a programmed necrocytosis among microgliocytes (brain macrophages). Nerve cells expressing Caspase 3 antigen at different times after a one-fold intramuscular introduction of copper nanoparticles $\left(1^{\text {st }}, 3^{\text {rd }}, 7^{\text {th }}, 14^{\text {th }}\right.$ day) have not been found. The rate of Caspase 3 expression of microgliocytes $1^{\text {st }}$ and $3^{\text {rd }}$ day after the introduction of copper nanoparticles has been unreliably increased in comparison with the control. However, 7 days after one-fold intramuscular introduction of copper nanoparticles the expression of Caspase 3 antigen has increased three times in comparison with the control group (Figures 4(a) and (b)). The expression of Caspase 3 in microgliocytes has decreased and corresponded to the indexes of the control animals after 14 days (Table 1).

After the enteral introduction of copper nanoparticles in a dosage of $2 \mathrm{mg} / \mathrm{kg}$ of an animal body weight the readiness of cells to a liver cells apoptosis after a threefold enteral introduction (total dosage is $6 \mathrm{mg} / \mathrm{kg}$ ) unreliably differs from the rates of apoptosis marker expression in a liver of control group animals (Table 2). At the same time after a threefold enteral introduction of copper nanoparticles (total dosage is $6 \mathrm{mg} / \mathrm{kg}$ ) the rate of Caspase 3 expression in proximal kidney tubules has increased 1.6-fold $(\mathrm{p}<0.05)$ compared with the control animals. 


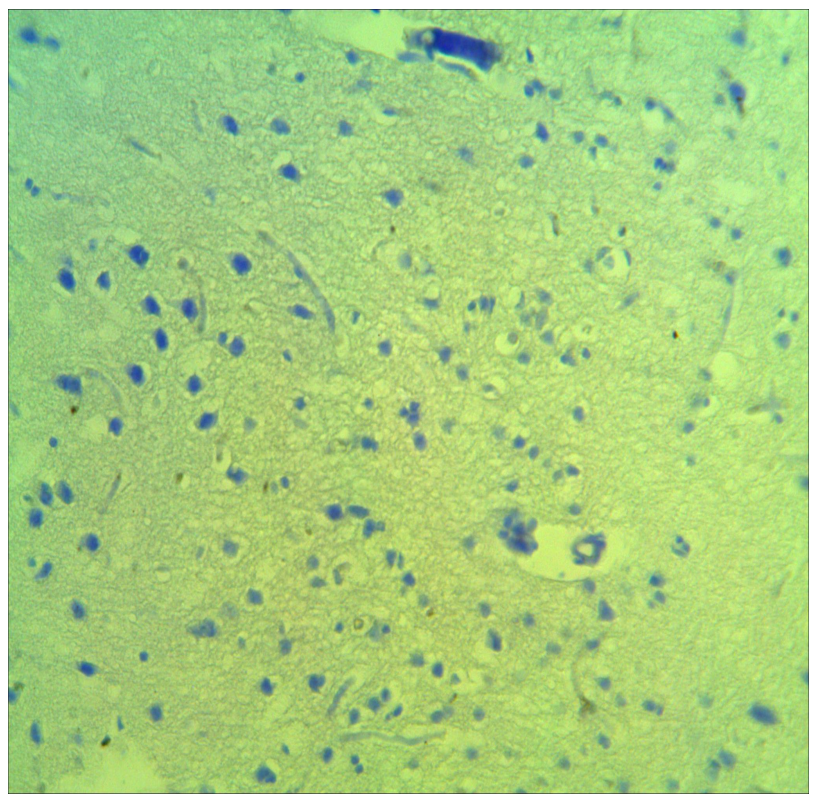

(a)

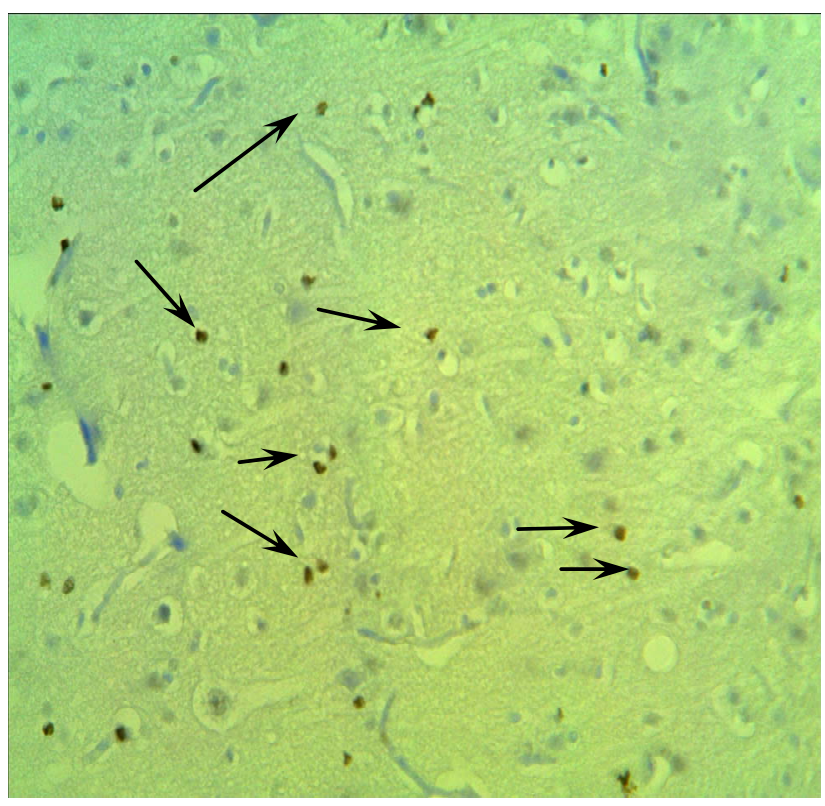

(b)

Figure 4. Histological liver section of the control (a) and the experimental rat (b) 1 day after the repeated intramuscular introduction of copper nanoparticles in the dosage of $2 \mathrm{mg} / \mathrm{kg}$.

Table 2. The indexes of Caspase 3 antigen expression (*) in liver cells after an enteral introduction of copper nanoparticles in the dosage of $2 \mathrm{mg} / \mathrm{kg}$ (in \%o).

\begin{tabular}{ccccccc}
\hline & \multicolumn{5}{c}{ Frequency of introduction of copper nanoparticles } \\
\cline { 2 - 7 } $\begin{array}{c}\text { Animal } \\
\text { groups }\end{array}$ & \multicolumn{2}{c}{ First introduction } & \multicolumn{2}{c}{ Second introduction } & \multicolumn{2}{c}{ Third introduction } \\
\cline { 2 - 7 } & \multicolumn{3}{c}{ Time after an introduction } \\
\cline { 2 - 7 } & 1 hour & 2 hour & 1 hour & 2 hour & 1 hour & 2 hour \\
\hline control & $0.5 \pm 0.04$ & $0.5 \pm 0.04$ & $0.5 \pm 0.04$ & $0.5 \pm 0.04$ & $0.5 \pm 0.04$ & $0.5 \pm 0.04$ \\
experiment & $0.6 \pm 0.03$ & $0.56 \pm 0.02$ & $0.65 \pm 0.05$ & $0.58 \pm 0.07$ & $0.69 \pm 0.02$ & $0.7 \pm 0.05$ \\
\hline
\end{tabular}

*Data presented as: average $(X) \pm$ standard error of the average $(S E)(n=1000)$.

Microgliocytes expressing Caspase 3 antigen (indicated with arrows) are revealed more in the sensomotor cortex zone of the experimental rat 1) compared with the control; 2) animal.

Therefore, at copper nanoparticles load increase on the organism, besides tissues restructuring, there is a signifycant increase of Caspase 3 expression in microgliocytes (brain macrophages) of the cortex 7 days after one-fold intramuscular introduction of copper nanoparticles $2 \mathrm{mg} / \mathrm{kg}$ ), in liver cells-3 days and 7 days after 3 -fold intramuscular introduction of copper nanoparticles (total dosage is 6 $\mathrm{mg} / \mathrm{kg}$ ), in proximal kidney tubules it happens 3 hours, 1 days, 3 days, and 7 days after 3 -fold intramuscular introduction of copper nanoparticles (total dosage is $6 \mathrm{mg} / \mathrm{kg}$ ), in spleen cells-3 hours, 1,3 , and 7 days after a 12 -fold intramuscular introduction of copper nanoparticles (total dosage is $24 \mathrm{mg} / \mathrm{kg}$ ).

The data indicate a high biological activity of copper nanoparticles when injected into the organism. Copper nanoparticles in a dosage of $2 \mathrm{mg} / \mathrm{kg}$ reveal neurotoxicity. Microgliocytes (brain macrophages) of the sensomotor cortex zone are the most sensitive to copper nanoparticles. And though the effect on them at the index of cells readiness to apoptosis was reversible ( 2 weeks after onefold introduction of copper nanoparticles in a dosage of 2 $\mathrm{mg} / \mathrm{kg}$ the level of apoptosis can be compared with that of the control group), its realization in case of further dosage increase of introduced nanoparticles will lead to the loss of cells that can cause neurodegenerative processes in the cortex.

Hepatotoxicity and nephrotoxicity of copper nanoparticles appear in a dosage of $6 \mathrm{mg} / \mathrm{kg}$. Moreover, the readiness to apoptosis is observed in peri-portal hepatocytes after 3 days, in kidney tubules epithelial cells 3 hours after 3-fold introduction of copper nanoparticles.

Spleen has been the least sensitive to the activity of 
copper nanoparticles was: cells of lymphoid follicles increased expression of Caspase 3 antigen in response to the introduction of copper nanoparticles in a dosage of 24 $\mathrm{mg} / \mathrm{kg}$, i.e. in a dosage close to LD100.

The established quality of copper nanoparticles in nontoxic dosages $(2 \mathrm{mg} / \mathrm{kg}-6 \mathrm{mg} / \mathrm{kg})$ to increase the cell readiness to apoptosis can be used in the chemotherapy of malignant neoplasms when there is apoptosis inhibittion of cells containing mutations. Silver nanoparticles as copper nanoparticles have the same quality to modulate apoptosis, based on that, there are bandages for healing wounds, burns and trophic ulcer. Due to this quality nanocrystalline silver reduces inflammatory stage of healing and thus eases an initial period of wound healing [1].

In addition, using data received from the conducted research, it seems obvious that index of cell readiness to apoptosis reflects the beginning of irreversible structural changes regardless of tissue peculiarity in response to the introduction of copper nanoparticles. All this allow us to suggest an apoptosis index as a criterion for the assessment of safe introduction of copper nanoparticles into organism of living systems. By this index we can judge acceptable dosages of introduced metal, target organs, establish optimal and safe methods of introducing nanoparticles into the organism for further use in the composition of drugs and biological preparations.

\section{REFERENCES}

[1] J. B. Wright, K. Lam, A. G. Buret, M. E. Olson and R. E. Burrell, "Early Healing Events in a Porcine Model of Contaminated Wounds: Effects of Nanocrystalline Silver on Matrix Metal loproteinases, Cell Apoptosis, and Healing," Wound Repair and Regeneration, Vol. 10, No. 3, 2002, pp. 141-151. doi:10.1046/j.1524-475X.2002.10308.X

[2] N. N. Glushchenko, O. A. Bogoslovskaya and I. P. Olkhovskaya, "Physical and Chemical Laws of Biological Effect of Superfine Metal Powders," Chemical Physics, Vol. 21, No. 4, 2002, pp. 79-86.

[3] T. A. Baytukalov, N. N. Glushchenko, O. A. Bogoslovskaya, I. P. Olkhovskaya, G. E. Folmanis and I. P. Arsentieva, "Wound Healing Composition and Method of Preparation," RF Patent No. 2296571, 2007.

[4] T. A. Baytukalov, N. N. Glushchenko, O. A. Bogoslovskaya, I. P. Olkhovskaya, I. O. Leipunsky, A. N. Zhigach and E. A. Shafranovsky, "Drug Accelerating Wound Healing," RF Patent No.2306141, 2007.

[5] "Publications for 1977-2010 Years on the Web Site of the Laboratory." http://www. nanobiology.narod.ru

[6] A. A. Shvedova and V. E. Kagan, "The Role of Nanotoxicology in Realizing the 'Helping without Harm' Paradigm of Nanomedicine: Lessons from Studies of Pulmonary Effects of Single-Walled Carbon Nanotubes," Journal of Internal Medicine, Vol. 276, No. 1, 2010, pp. 106118.
[7] H. S. Sharma, S. Hussain, J. Schlager, S. F. Ali and A. Sharma, "Influence of Nanoparticles on Blood-Brain Barrier Permeability and Brain Edema Formation in Rats," Acta Neurochirurgica Supplementum, Vol. 106, 2010, pp. 359364. doi:10.1007/978-3-211-98811-4 65

[8] Z. Yang, Z. W. Liu, R. P. Allaker, P. Reip, J. Oxford, Z. Ahmad and G. Ren, "A Review of Nanoparticle Functionality and Toxicity on the Central Nervous System," Journal of the Royal Society Interface, Vol. 7, Suppl. 4, 2010, pp. 411-422.

[9] J. Wang, M. F. Rahman, H. M. Duhart, G. D. Newport, T. A. Patterson, R. C. Murdock, S. M. Hussain, J. J. Schlager and S. F. Ali, "Expression Changes of Dopaminergic System-Related Genes in PC12 Cells Induced by Manganese, Silver, or Copper Nanoparticles," Neurotoxicology, Vol. 30, No. 6, 2009, pp. 926-933. doi:10.1016/j.neuro.2009.09.005

[10] M. Y. Liao, R. H. Lei, C. Q. Wu, B. H. Yang, H. Z. Ma, C. Shi, Q. J. Wang, Q. X. Wang and Y. Yuan, "Integrated Metabolomic Analysis of the Nano-Sized Copper ParticleInduced Hepatotoxicity and Nephrotoxicity in Rats: A Rapid in Vivo Screening Method for Nanotoxicity," Toxicology and Applied Pharmacology, Vol. 232, No. 2, 2008, pp. 292-301. doi:10.1016/j.taap.2008.06.026

[11] H. L. Karlsson, P. Cronholm, J. Gustafsson and L. Möller, "Copper Oxide Nanoparticles are Highly Toxic: A Comparison between Metal Oxide Nanoparticles and Carbon Nanotubes," Chemical Research in Toxicology, Vol. 21, No. 9, 2008, pp. 1726-1732. doi:10.1021/tx800064j

[12] Z. Chen, H. Meng, G. Xing, C. Chen, Y. Zhao, G. Jia, T. Wang, H. Yuan, C. Ye, F. Zhao, Z. Chai, C. Zhu, X. Fang, B. Ma and L. Wan, "Acute Toxicological Effects of Copper Nanoparticles in Vivo," Toxicology Letters, Vol. 163, No. 2, 2006, pp. 109-120. doi:10.1016/j.toxlet.2005.10.003

[13] A. R. Murray, E. Kisin, S. S. Leonard, S. H. Young, C. Kommineni, V. E. Kagan, V. Castranova and A. A. Shvedova, "Oxidative Stress and Inflammatory Response in Dermal Toxicity of Single-Walled Carbon Nanotubes," Toxicology, Vol. 257, No. 3, 2009, pp. 161-171. doi:10.1016/j.tox.2008.12.023

[14] G. G. Onishchenko, "The Concept of Toxicological Studies, Estimated Risk Methodology, Methods of Identification and Quantification of Nanomaterials," Resolution 79, Registered in the Russian Ministry of Justice, Registration No. 10528, 2007.

[15] M. Ya. Gen and A. V. Miller, "Author's Certificate of the USSR No. 814432," Bulletin of Discoveries, No. 11, 1981, pp. 25-28.

[16] A. N. Zhigach, I. O. Leipunsky, M. L. Kuskov, N. I. Stoenko and V. B. Storozhev, "Facility for Producing and Studying Physical and Chemical Properties of Metal Nanoparticles," Instruments and Experimental Techniques, Vol. 4, No. 6, 2000, pp.122-125.

[17] E. Peirce, "Histochemistry, Theoretical and Applied," Churchill, Moscow, 1962, pp. 962-968.

[18] A. A. Rakhmetova, T. P. Alekseeva, O. A. Bogoslovskaya, I. O. Leipunsky, I. P. Olkhovskaya, A. N. Zhigach and N. N. Glushchenko, "Wound Healing Properties of Cop- 
per Nanoparticles Depending on Their Physical and Chemical Characteristics," Russian Nanotechnology, Vol. 5, No. 3-4, 2010, pp. 102-111.

[19] N. N. Glushchenko, I. P. Olkhovskaya, T. V. Pleteneva, L. D. Fatkullina, Yu. A. Ershov and Yu. I. Fedorov, "The Biological Effect of Superfine Metal Powders," Izvestiya $A N$, Vol. 6, No.3, 1989, pp. 415-418.

[20] O. A. Bogoslovskaya, E. A. Sizova, V. S. Polyakova, S. A. Miroshnikov, I. O. Leipunsky, I. P. Olkhovskaya and N. N. Glushchenko, "The Study of Safe Introduction of Copper Nanoparticles with Different Physical-Chemical Characteristics into Organisms of Animals," Bulletin of $O S U$, Vol. 32, No. 2, 2009, pp. 124-128.

[21] V. A. Galitsky, "The Emergence of Eukaryotic Cells and the Origin of Apoptosis," Cytology, Vol. 47, No. 2, 2005, pp. 103-108.

[22] A. V. Kudrin and A. A. Zhavoronkov, "The Role of Minor Constituences and Calcium in the Regulation of Apoptosis," Successes of Modern Biology, Vol. 118, 1998, pp. 7-15.

[23] N. I. Kaletina and G. I. Kaletin, "Minor ConstituencesBiological Controls," Academy of Science, No. 1, 2007, pp. 50-60.

[24] O. A. Bogoslovskaya, L. A. Volodina, I. O. Leipunsky, A. N. Zhigach, T. P. Alekseeva, A. A. Rakhmetova, M. N. Ovsyannikova, I. P. Olkhovskaya and N. N. Glushchenko, "The Effect of Copper Nanoparticles-Components of Particulate Matters of Thermal Power Plants Smoke Carryovers on Bacterial Cells," Izvestiya AN, Vol. 4, No. 2, 2010, pp. 105-108. 